\title{
Avaliação econômica de projetos de transporte: melhores práticas e recomendações para o Brasil*
}

\author{
Marta Corrêa Dalbem** \\ Luiz Brandão*** \\ T. Diana L. van Aduard de Macedo-Soares****
}

SumÁrio: 1. Introdução; 2. Métodos de pesquisa; 3. O estado da arte em avaliação econômica de projetos de transporte; 4. Brasil: práticas atuais de avaliação econômica de projetos de transporte; 5 . Limitações observadas e recomendações para a metodologia brasileira; 6. Conclusões.

Summary: 1. Introduction; 2 . Research methods; 3 . The state of the art in economic appraisal of transportation projects; 4. Brazil: current practices for economic appraisal of transportation projects; 5 . Detected limitations and recommendations for the Brazilian methodology; 6. Conclusions.

Palavras-chave: avaliação econômica; transportes; impactos sociais; Brasil.

KEY WORDs: economic appraisal; transportation infrastructure; social impacts; Brazil.

Este artigo apresenta os resultados de uma investigação bibliográfica e documental sobre avaliação econômica de projetos, identificando o estado da arte e as melhores práticas internacionais nessa área, bem como os critérios atualmente adotados no Brasil. Com base nisso, faz recomendações para a melhoria das metodologias no Brasil, especialmente no que concerne à avaliação dos benefícios de segurança, economias de tempo e desenvolvimento social oriundos de projetos de infraestrutura de transporte.

\footnotetext{
* Artigo recebido em maio e aceito em nov. 2009.

** Mestre em administração pela Universidade Federal do Rio de Janeiro (Coppead/UFRJ, doutoranda no Departamento de Administração de Empresas da Escola de Negócios da Pontifícia Universidade Católica do Rio de Janeiro (IAG/PUC-Rio). Endereço: Rua Marquês de São Vicente, 225 — Gávea - CEP 22453-900, Rio de Janeiro, RJ, Brasil. E-mail: martadalbem@iag.puc-rio.br. *** Doutor pela PUC-Rio, MSc e MBA pela Stanford University. Professor assistente do Departamento de Administração de Empresas do IAG/PUC-Rio. Endereço: Rua Marquês de São Vicente, 225 — Gávea - CEP 22453-900, Rio de Janeiro, RJ, Brasil. E-mail: brandao@iag.puc-rio.br. $* * * *$ Doutora pela University of Montreal, Canadá. Professora associada do Departamento de Administração de Empresas do IAG/PUC-Rio. Endereço: Rua Marquês de São Vicente, 225 — Gávea — CEP 22453-900, Rio de Janeiro, RJ, Brasil. E-mail: redes@strategy-research.com.
} 


\section{Economic appraisal of transportation projects: best practices and recommendations for Brazil}

This article presents the results of an extensive documental research and literature review of worldwide procedures for economic project appraisal, and identifies best practices and state-of-the-art techniques in this area, as well as the criteria adopted in Brazil for this purpose. In the light of international benchmarks, it makes recommendations for improvements in the use of these methods in Brazil regarding the appraisal of safety measures, time savings benefits and social development that result from transportation-related infrastructure projects.

\section{Introdução}

Do ponto de vista da iniciativa privada, a viabilidade de um projeto é determinada por meio de uma análise monetária que comprove que suas receitas esperadas serão maiores do que os seus custos de investimento e de operação. Do ponto de vista da sociedade, no entanto, os benefícios futuros de um projeto têm uma abrangência mais ampla do que apenas a geração de receitas, e podem incluir fatores como o desenvolvimento econômico de um setor, de uma região, melhoria da qualidade de vida, benefícios de redução de tempo de transporte, de acidentes e outros. Dessa forma, no contexto de uma avaliação econômica, um projeto pode ser considerado de interesse para a sociedade ainda que não gere o retorno financeiro exigido pelo investidor privado.

Metodologias de avaliação econômica foram inicialmente desenvolvidas nos países da Europa e nos Estados Unidos na década de 1960, seguindo a tendência de um maior acompanhamento e questionamento por parte da sociedade quanto à melhor forma de investir recursos escassos. Atualmente já existem algumas práticas consolidadas nesses países, embora ainda continue grande o desafio de transformar os potenciais benefícios econômicos de um projeto em valores tangíveis. No Brasil, embora já existam algumas normas e diretrizes que levam em consideração esses efeitos em projetos de transporte, não há ainda uma cultura consolidada nesse sentido, tampouco um conjunto de práticas definidas para o uso da avaliação econômica como ferramenta de decisão de investimentos públicos.

Dessa forma, este artigo pretende responder às seguintes perguntas: Quais as práticas no mundo para a avaliação econômica de projetos de transporte? Quais as práticas adotadas no Brasil? Há como melhorar o processo brasileiro de avaliação econômica de projetos?

Aqui limitaremos nossa análise aos impactos sociais de redução de acidentes, economia de tempo dos usuários e desenvolvimento econômico. 
Este artigo está organizado da seguinte forma: a próxima seção detalha a metodologia utilizada, seguida por uma explanação na seção 3 das diferenças entre avaliação financeira e econômica e por uma descrição do estado da arte em avaliação econômica. A seção 4 apresenta as práticas adotadas no Brasil em projetos de infraestrutura de transportes. Na seção 5 , são enfatizados os pontos em que o processo brasileiro de avaliação de projetos pode ser melhorado, à luz da experiência em outros países. Finalmente apresentamos as conclusões e considerações a respeito dos benefícios e das dificuldades para a implantação de critérios quantitativos de avaliação econômica e sugerimos temas para pesquisas futuras.

\section{Métodos de pesquisa}

A pesquisa percorreu as etapas a seguir.

- Pesquisa bibliográfica, com foco na Inglaterra, berço da avaliação econômica e das PPPs. Utilizou-se também como referência a Comunidade Europeia, que tem passado por processo de uniformização de práticas, também no que se refere à avaliação econômica. $O$ estudo também analisou pesquisa conduzida no Japão sobre avaliação de acidentes, de modo a identificar dificuldades ao transpor práticas adotadas em outros países para um ambiente cultural bastante diverso.

v Pesquisa documental de manuais e diretrizes do World Bank para a avaliação e aprovação de projetos de infraestrutura e de transporte.

- Pesquisa documental dos manuais e diretrizes para avaliação de projetos rodoviários no Brasil (Instituto de Pesquisas Rodoviárias - IPR, e Departamento Nacional de Infraestrutura de Transportes — DNIT).

- Proposição de processos e práticas para a avaliação econômica de projetos de transporte brasileiros.

\section{0 estado da arte em avaliação econômica de projetos de transporte}

Samuelson (1954) lançou as bases para o aumento de pesquisas em avaliação econômica. Em seu artigo, o autor alertava que, à exceção de autores como 
Sax, Lindahl, Wicksell, Musgrave e Bowen, os economistas da época negligenciavam sobremaneira a teoria do dispêndio público ótimo e direcionavam a maior parte de sua energia na teoria da taxação. Alguns dos primeiros trabalhos sobre o tema avaliação econômica datam das décadas de 1950 e 1960, tais como Arrow (1963) e Beesley (1965), período a partir do qual se buscou maior eficiência na gestão pública. Esse movimento foi intensificado na década de 1980, especialmente na Inglaterra e na Holanda. Em 1996, as práticas e sugestões apresentadas na literatura existente foram compiladas no World Bank handbook (World Bank, 1996) doravante WBH, que contém as diretrizes atualmente utilizadas pelo World Bank na avaliação econômica de projetos com o intuito de identificar o seu beneficio para a sociedade. As suas principais recomendações, e também as do World Bank transport notes (2005), estão descritas a seguir.

\section{Avaliação econômica: principais conceitos}

Na avaliação financeira, procura-se identificar se o projeto é autossustentável financeiramente, enquanto na avaliação econômica o foco é definir se o projeto gera benefícios líquidos para a sociedade, aqui entendidos como os benefícios incrementais causados pelo projeto. Dessa forma, em projeto que capture demanda já atendida por outros meios, deve ser considerado apenas o seu benefício adicional para a sociedade e não a demanda total atendida.

Outro item a lembrar são as eventuais distorções causadas por controles de preço, de oferta, tarifas, cotas de importação e exportação ou subsídios; nesses casos, deve ser considerado o preço-sombra desse insumo ou produto, que corresponde ao seu preço livre de mercado. Intervenções governamentais no câmbio podem gerar também a necessidade de se usar paridades-sombra no caso de importação e exportação de insumos. As diferenças entre preços reais e preços-sombra devem ser alocadas a quem está perdendo ou ganhando nesse mercado imperfeito.

Cabe aqui lembrar que a informação sobre quem ganha ou perde com o projeto é fundamental para identificar se ele atenderá a objetivos tais como o de distribuição mais igualitária de riqueza ou, ainda, se não faria sentido os beneficiários serem também financiadores do projeto, uma informação especialmente útil em negociações de PPPs, por exemplo. A tabela 1 ilustra uma análise hipotética de ganhadores/perdedores de um projeto. 
Tabela 1

Exemplo de análise de ganhadores versus perdedores de um projeto

\begin{tabular}{|lccccc|}
\hline Custos/benefícios & Projeto & Governo & Competidores & Fornecedores & Total = Sociedade \\
\hline Receitas & 6.509 & 79 & $(539)$ & 0 & 6.049 \\
Custos locais diretos & $(3.012)$ & $(37)$ & 445 & 56 & $(2.548)$ \\
Custos de importação & $(1.890)$ & $(178)^{*}$ & 0 & 0 & $(2.068)$ \\
Imposto de renda & $(873)$ & 823 & 50 & 0 & 0 \\
Benefício líquido & 734 & 687 & $(44)$ & 56 & 1.433 \\
\hline
\end{tabular}

Fonte: Adaptado de World Bank (1996:106).

* Efeito das distorções no câmbio em função de subsídios à exportação e taxação de importações.

\section{Benefícios do projeto - regra da metade*}

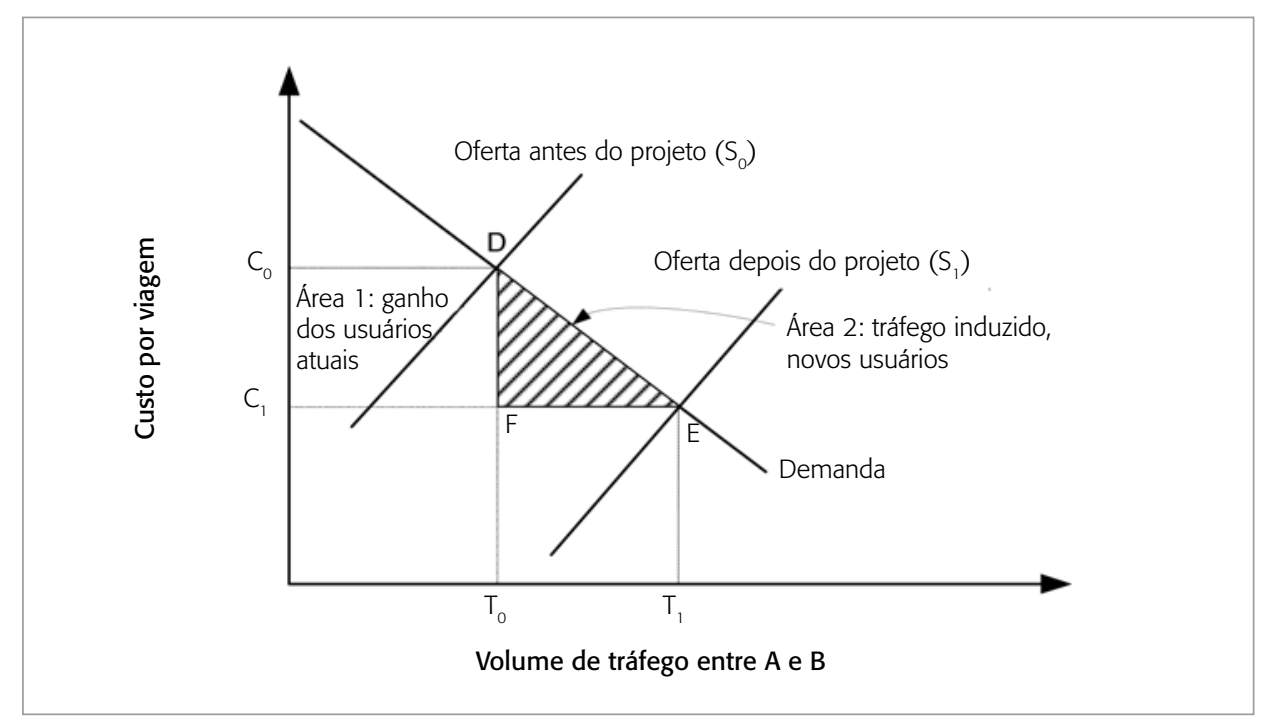

Fonte: Adaptado de World Bank TRN 11 (2005:4) e WBH (1996:26-27).

* O excedente do consumidor é representado por área $1\left(C_{0}-C_{1}-F-D-C_{0}\right)+$ área 2 (D-E-F) na figura; o benefício líquido para a sociedade é apenas a área 2, caso o ganho pela redução de preços tenha representado perda para outros membros da sociedade.

Um projeto pode também gerar reduções de custo para os usuários e induzir aumento de tráfego. Um dos métodos adotados para se estimar esse benefício é a regra da metade, ilustrada na figura. Uma redução na tarifa de pedágio de uma rodovia de $C_{0}$ para $C_{1}$ acarreta um ganho para os atuais usuários desse serviço, representado pela área 1 da figura. Por outro lado, uma menor tarifa de pedágio tende a aumentar o volume de tráfego para $T_{1}$, acima 
do volume atual $T_{0}$. A área do triângulo representado pela área 2 , definida pelo aumento do tráfego e pela redução de custo, reflete o ganho econômico líquido do projeto na maioria dos casos (dado que, quando se fala de ganho econômico, temos que considerar todos os componentes da sociedade, inclusive aqueles que deixaram de ganhar com a nova situação - por exemplo a concessionária da rodovia, que deixa de ganhar o equivalente à área 1).

Outro ponto a considerar em avaliação econômica são os impactos fiscais do projeto; é importante notar que eles são maiores que os de fato desembolsados, já que os recursos públicos têm um custo marginal. Assim, um projeto que faz uso líquido de recursos públicos tem o seu valor presente líquido econômico diminuído por esse efeito, enquanto um projeto que é gerador líquido de recursos públicos tem seu VPL econômico aumentado. Nem sempre é simples estimar esses efeitos, mas nos casos em que o projeto demanda recursos públicos e tem VPL econômico baixo, esse efeito pode alterar a decisão e deve, portanto, ser estimado (Devajaran, Squire e Suthirwart-Narueput, 1995; Harberger, 1995, apud WBH).

Finalmente, outro importante conceito em avaliação econômica são as externalidades, aqui entendidas, seguindo o conceito utilizado pelo $W B H$ (1996:25), como os impactos causados a terceiros, pelos quais o projeto não está sendo onerado (por exemplo, deterioração de prédios próximos em função da poluição gerada pelo projeto) ou, ainda, benefícios a terceiros, como segurança, que não geram receitas para o projeto. O Banco Mundial recomenda que essas externalidades sejam quantificadas monetariamente sempre que possível, e veremos, a seguir, como os principais critérios de avaliação econômica buscam realizar isso.

O critério cost-benefit analysis (CBA) analisa alternativas de investimento via quantificação monetária do maior número possível de custos e benefícios e utiliza os conceitos anteriormente descritos de preços-sombra, benefícios líquidos etc. No caso das externalidades, tal quantificação monetária se dá usualmente por métodos como os de valoração contingente, que procuram determinar a disposição dos usuários para pagar (willingness to pay — WTP) por um determinado item ou serviço. Nos estudos para se determinar o WTP são aplicados questionários a uma amostra representativa da população, em que o usuário é solicitado a fornecer valores monetários para uma lista de benefícios, como o quanto o indivíduo pagaria para ter uma probabilidade $x \%$ menor de sofrer um acidente ou para chegar $y$ minutos mais cedo ao seu local de destino. Podem existir dificuldades na determinação do WTP devido ao custo alto da pesquisa, à pouca familiaridade de algumas populações com o conceito de probabilidade, e por decisões nem sempre coerentes entre si ou 
racionais. Apesar disto, têm-se obtido bons resultados nas tentativas feitas em países desenvolvidos, a exemplo da pesquisa de Jones-Lee, Hammerton e Philips (1985), que procurou determinar o WTP no Reino Unido relativo a melhorias de segurança.

Quando não há como monetizar todos os efeitos de um projeto, uma alternativa é usar o critério de custo-efetividade, ou cost effectiveness analysis (CEA). Por esse critério, os benefícios são ainda quantificáveis, porém, por meio de outros resultados como, por exemplo, quantas pessoas ou empresas, hoje não atendidas, passarão a usufruir da nova infraestrutura. Tais benefícios, ponderados pelo custo total do projeto, tornam possível ordenar projetos alternativos por ordem de efetividade. Embora seja um bom critério para escolher entre alternativas, o CEA não contribui para a decisão investir/não investir (World Bank, 2005a:18). O CEA tem sido muito utilizado, porém ele pressupõe que a decisão é pautada por um único objetivo. Para escolher entre projetos que atendem a objetivos diferentes ou em setores diferentes, a recomendação é usar o CBA (World Bank, 1996, 2005a), sempre que possível.

Quando existem múltiplos objetivos a serem atingidos em um projeto, uma terceira alternativa é usar análise multicritério (MCA, em inglês), bem detalhada no trabalho de Dodgson e colaboradores (2001). Na MCA, os diversos objetivos são ponderados por sua importância relativa, gerando uma nota que, dividida pelo custo do projeto, produz um índice que permite a comparação com outros projetos. A atribuição desses pesos pode ser transparente, na medida em que especialistas e a população sejam chamados a opinar, porém um forte componente de subjetividade continuará sempre existindo nesse processo.

Quando os objetivos finais do projeto não forem facilmente quantificáveis, resta a análise qualitativa. No entanto, restringir a avaliação econômica a dados qualitativos pode aumentar muito a subjetividade, a ponto de afetar a transparência e a imparcialidade da análise.

Finalmente, o trabalho de Grant-Muller e outros (2001) nos dá uma ideia de como se tem feito avaliação econômica, na prática. Em todos os 14 países europeus por eles analisados, a avaliação econômica é usada para priorizar projetos, mas não para tomar uma decisão final. Há um reconhecimento de que outros fatores - políticos, culturais - devem ser também levados em consideração na decisão final. Isso dificulta a uniformização de práticas na Europa e representa um desafio especialmente naqueles projetos cujos impactos transcendem as fronteiras nacionais. O Banco Mundial (2005e:18-19) também alerta que o CBA ainda não incorpora desenvolvimento econômico, emprego, redução de pobreza, na análise. Assim, o Banco Mundial (2005c:1) sugere que o CEA seja usado para uma primeira triagem dos projetos, escolhendo apenas 
os que atendam aos objetivos de difícil monetização. Em uma segunda fase, uma análise CBA identificaria os projetos economicamente viáveis.

Apesar das dificuldades, nota-se pelo trabalho de Grant-Muller e colaboradores que nos países europeus os itens segurança e economia de tempo são unanimemente avaliados por CBA e, em alguns desses países, complementa-se a avaliação através do critério MCA. Esses dois itens - segurança e economia de tempo - serão detalhados a seguir.

\section{Benefícios de segurança}

Nellthorp e outros (1998, apud World Bank, 2005g) utilizam o critério CBA para analisar os benefícios resultantes de investimentos em segurança, e classificam os acidentes com relação aos seus custos e à sua gravidade. Os custos dos acidentes podem ser divididos em duas categorias.

- Custos relacionados ao acidente em si: danos materiais aos veículos e a obras civis, mão de obra para reparos, serviços de emergência, custos legais, processuais, seguro, congestionamentos e atrasos causados a terceiros.

- Custos relacionados aos acidentados: menor geração de riqueza, custos médicos, custos relacionados à dor, sofrimento e pesar pela perda de entes queridos. De acordo com a gravidade, os acidentes também podem ser classificados como:

v acidentes fatais - são aqueles que resultam em morte até 30 dias após o evento;

v acidentes graves — são os que requerem internação hospitalar e que geram sequelas, porém sem fatalidades;

v acidentes leves - são os que não geram internação hospitalar ou que, mesmo exigindo internação, não geram sequelas físicas relevantes.

Essa classificação é uma simplificação das 10 classes de acidentes usadas no Reino Unido (Jones-Lee et al., 1993, apud Koyama e Takeuchi, 2004). No Japão (Koyama e Takeuchi, 2004), a classificação dos acidentes em 14 níveis está correlacionada ao nível de incapacitação para o trabalho, como perdas de visão ou de membros, por exemplo, que é inclusive uma classificação bastante similar à utilizada por seguradoras brasileiras para definir o percentual de indenizações a ser pago em acidentes (DNIT/IPR, 2004). Vale notar que, ao aplicar questionários WTP no Japão, Koyama e Takeuchi con- 
cluíram que a classificação inglesa foi melhor compreendida que a japonesa pelos entrevistados.

Avaliar os benefícios da segurança envolve, portanto, avaliar a redução de custos de acidentes, acima detalhados. Os custos de acidentes graves e leves são, em geral, estimados por percentuais do custo de acidentes fatais. Dessa forma, a maior dificuldade reside, primeiro, em definir o valor de uma vida em termos monetários; segundo, em definir pesos para os diversos níveis de gravidade dos acidentes.

\section{Determinação do valor de uma vida}

Jacobs (1995) resume algumas formas para atribuir valor a uma "vida econômica".

1. Rendimentos brutos perdidos: renda que seria gerada pelo indivíduo, caso não tivesse falecido.

2. Rendimentos líquidos perdidos, deduzido o consumo futuro: aqui, a perspectiva é a geração de riqueza líquida, para a sociedade, daquela vida.

3. Valor de apólices de seguro de vida.

4. Indenizações concedidas em corte judicial aos dependentes das vítimas.

5. Valores alocados pelos governos a programas de prevenção de acidentes e segurança.

6. Valor da vida estatística, que consiste na aplicação do conceito WTP. O valor que os entrevistados se dispõem a pagar, dividido pela redução de risco obtida, gera uma estimativa do value of statistical life (VoSL), ou seja, o valor de uma vida estatística. Assim, se a mediana dos relatos indica uma disposição para pagar \$ 1 para reduzir a chance de morte em 1/10 mil, isso gera um VoSL de \$ 10 mil.

Outra forma, mencionada por Markandya (1998), é o método de preços hedônicos, baseado no prêmio por periculosidade recebido por trabalhadores com maior exposição ao risco. Essa alternativa é também objeto de algumas críticas, dado que pressupõe que os trabalhadores têm de fato escolha entre assumir ou não trabalhos arriscados, o que nem sempre é verdade, especialmente em países subdesenvolvidos. Mesmo quando a escolha é possível, pode haver viés, pois indivíduos menos avessos ao risco tendem a optar por funções 
arriscadas. Assim, apesar de ter seus méritos e ser amplamente utilizada, não nos parece ser a melhor forma para estimar o VoSL em um país como o Brasil. ${ }^{1}$

As alternativas 2, 3, 4 e 5, anteriormente descritas, também parecem de pouca valia em países com grandes desigualdades sociais e nos quais o cidadão médio gera pouca receita líquida, raramente faz seguros de vida, onde há casos estatisticamente insignificantes de indenizações via corte judicial e onde a alocação de recursos públicos, escassos, não reflete necessariamente a preocupação da sociedade com o assunto. Dessa forma, consideramos que as alternativas mais viáveis de monetização da segurança no Brasil são as alternativas 1 (rendimentos brutos perdidos) e a 6 (WTP). O Banco Mundial (World Bank, 2005g) alerta que o método de rendimentos brutos perdidos geraria um valor mínimo a ser atribuído à vida e que a diferença entre os valores gerados por esse método e pela aplicação do conceito de WTP pode ser muito significativa.

Uma forma sugerida por Jacobs (1995, apud World Bank, 2005g) para superar esse problema é apurar todos os custos monetizáveis, somando-lhes um percentual que busca estimar o valor da "dor, sofrimento e pesar". Os percentuais seriam: acidente fatal (38\%); acidente grave (100\%); acidente leve (8\%). Não há nenhuma indicação da lógica subjacente a esses números, ao contrário, o Banco Mundial (World Bank, 2005g) alerta que esses percentuais são essencialmente arbitrários.

No Brasil, o DNIT/IPR (2004) sugere um valor para "dor, sofrimento e pesar" de aproximadamente US\$ 3.500 por acidente, com ou sem vítimas. Esse número equivale a $20 \%$ do custo total/acidente no Brasil, em moeda de 2004. No Japão, esse percentual é de $40 \%$, mesmo sem usar o conceito WTP. Com WTP, esse percentual sobe para 69\% na pesquisa de Koyama e Takeuchi (2004). Nos acidentes fatais, o valor encontrado no Brasil para "dor, sofrimento e pesar" foi de US\$ $35 \mathrm{mil} /$ fatalidade, equivalente a $27 \%$ do custo total/ acidente fatal; na Dinamarca, esse percentual é de 67\% (Grant-Muller et al., 2001:246), o que faz o percentual adotado pelo DNIT parecer muito baixo.

A alternativa indicada pela literatura seria transpor resultados WTP de outros países para o país em questão, tentando nesse caso superar a dificuldade de que o WTP está atavicamente ligado não só a traços culturais, mas também ao poder aquisitivo da população. Cropper (apud World Bank, 2005g) e também Markandya (1998) sugerem a seguinte conversão:

\footnotetext{
${ }^{1}$ Um bom exemplo de aplicação desse modelo no Brasil pode ser encontrado em Paixão (2009), que trata do impacto da violência no preço de imóveis em Belo Horizonte.
} 


$$
W T P_{i}=W T P_{j} \times\left[\frac{P P P P I B_{i}}{P P P P I B_{j}}\right]^{\xi}
$$

Onde:

$i=$ país do projeto;

$j=$ país onde o WTP foi medido;

$P P P P I B=P I B$ ajustado pela paridade do poder de compra;

$\xi=$ elasticidade-renda do WTP em relação ao PPP PIB.

A elasticidade $\xi$ requer uma análise mais detalhada. Estudo de JonesLee, Hammerton e Philips (1985) chegou a 0,30; Mitchel e Carson (1986, apud Markandya, 1998) chegaram a um valor de 0,35; Cropper (apud World Bank, 2005g) menciona resultados entre 0,30 e 0,60. Há dúvidas se essa elasticidade-renda intrapaís pode ser extrapolada para diferença de renda entre países, e Cropper menciona que elasticidades menores que 1,0 têm gerado valores considerados exagerados em seus países. Assim, embora não haja consenso quanto a um parâmetro ideal, Cropper sugere usar a elasticidade de 1,0 e fazer análises de sensibilidade dos resultados a valores menores que a unidade.

Outra limitação ao se transpor resultados WTP de um país para outro é que isso pressupõe uma relação linear entre "risco" e "valor a pagar pela redução de risco" e essa premissa pode não ser aceitável em situações muito diversas da situação base (Markandya, 1998). Esse problema é também mencionado no estudo de Koyama e Takeuchi (2004): no Japão, a frequência de fatalidades em estradas era de 8,2/100 mil habitantes, enquanto no Reino Unido era de 5,9/100 mil habitantes em 1992, o que de fato altera a percepção de risco nesses dois países. Vale notar que no Brasil o número de fatalidades em acidentes de trânsito, em 2005, foi de aproximadamente 20,0/100 mil. ${ }^{2}$

Markandya (1998) também alerta para os riscos de se transpor valores VoSL de um país para outro onde a expectativa de vida pode ser muito diferente. Há evidências empíricas de que a elasticidade do WTP ao risco depende da idade, isto é, parece seguir uma curva em U invertida em que o ápice acontece próximo à idade média da população (Jones-Lee, Hammerton e Philips, 1985). Em pesquisa feita na Inglaterra no início da década de 1980, Jones-Lee (1989, apud Markandya, 1998:12) chegou aos percentuais apresentados na tabela 2 .

${ }^{2}$ Disponível em: <www.infoseg.gov.br/renaest $>$. 
Tabela 2

Valor estatístico de uma vida (VoSL) como percentual do valor atribuído aos 40 anos

\begin{tabular}{|lllllllllllll|}
\hline Idade & 20 & 25 & 30 & 35 & 40 & 45 & 50 & 55 & 60 & 65 & 70 & 75 \\
VoSL & 68 & 79 & 88 & 95 & 100 & 103 & 104 & 102 & 99 & 94 & 86 & 77 \\
\hline
\end{tabular}

Fonte: Jones-Lee (1989), apud Markandya (1998).

Como referência, o apêndice 1 apresenta os valores encontrados em alguns trabalhos acadêmicos para o VoSL ou, ainda, para o custo de um acidente fatal. Nota-se que as simplificações adotadas para o Brasil parecem inapropriadas, sugerindo que estudos mais sofisticados, como o WTP, podem ser necessários.

\section{Determinação dos pesos para os diversos níveis de gravidade de acidentes}

Jones-Lee e coautores (1993, 1995, apud Koyama e Takeuchi, 2004) desenvolveram procedimentos, baseados no conceito de quality adjusted life year approach (QALY), em que se procura estimar o tempo que um indivíduo deseja a mais de vida a partir de um estado particular de saúde e de sua idade. O índice QALY ajuda a atribuir um valor monetário para um determinado tipo de sequela ou sofrimento gerado por acidentes e o valor obtido é proporcional ao VoSL, atribuído à perda de uma vida.

O peso QALY tem sido estimado através de três processos, conforme Koyama e Takeuchi (2004).

- Escala analógica visual: os respondentes indicam numa régua com uma escala de 0 (morte) a 1 (saúde completa), onde o seu estado de saúde particular se encontra.

- Troca de tempo de vida por saúde: os respondentes devem escolher entre viver $T$ tempo no estado particular de saúde, ou menos tempo $(t)$ com saúde completa.

- Teoria dos jogos: o respondente tem a opção de escolher ou não um procedimento que o retornará ao estado de saúde completa, mas que tem uma probabilidade $p$ de levá-lo à morte. 


\section{Custo total de acidentes}

Uma vez estimados os custos diretos e subjetivos para cada tipo de acidente, é necessário determinar o número esperado de acidentes para o projeto em análise. Há modelos que fazem essas previsões a partir das características físicas da rodovia, tais como sinuosidade, volume de tráfego etc., alimentados com as estatísticas locais de acidentes em rodovias correlatas. O Banco Mundial (World Bank, 2005g) menciona que ao software Highway Demand Management System Software (HDM), utilizado no Brasil e em diversos países do mundo, seria incorporada modelagem para previsão do número de acidentes. A partir desse número esperado de acidentes de um projeto específico e dos custos por acidente pode-se inferir o custo total relativo a acidentes de um novo projeto e avaliar quanto um projeto mais seguro trará em benefícios para a sociedade.

\section{Benefícios de redução do tempo de viagem}

Os benefícios advindos da redução do tempo de viagem podem chegar a 80\% dos benefícios totais de um projeto em países desenvolvidos (World Bank, 2005f:1). O princípio básico na avaliação do tempo é a de que os indivíduos, sujeitos à restrição das horas do dia que podem devotar ao trabalho, ao lazer e ao tempo que perdem em trânsito, procuram maximizar sua riqueza e bemestar. Essa preferência pode ser estimada através de pesquisas WTP, em que se procura identificar a preferência declarada dos indivíduos pelo tipo de transporte, em diversas situações. São normalmente feitas as seguintes distinções (World Bank, 2005a):

v tempo de trabalho - avaliado pelo salário envolvido, acrescido dos demais custos fixos e trabalhistas incorridos pelo empregador;

- tempo de não trabalho (lazer, negócios pessoais, trajeto trabalho/casa) Gwilliam (1997) e o Transport 2002/UK (apud World Bank, 2005f) relatam pesquisas WTP que indicaram uma valoração de tempo de lazer em $22-39 \%$ do valor do tempo de trabalho na Holanda, similar a resultados no Reino Unido e Suécia, e 62\% em Bangladesh. Grant-Muller e outros (2001) observaram que nem todos os 14 países europeus analisados em sua pesquisa dão tratamento diferenciado a "tempo de não trabalho", mas a maioria o faz, atribuindo valores entre $10 \%$ a $50 \%$ do valor do "tempo de trabalho" (média $=20 \%$ ). O Banco Mundial recomenda como regra geral valorar a 
hora de não trabalho despendida em transporte em 30\% da renda familiar bruta/hora para adultos e 15\% para crianças. Gwilliam (1997) alerta que, a menos que o projeto em questão envolva pagamento pelos benefícios auferidos (pedágios), recomenda-se considerar a renda média do país nos cálculos do valor do tempo, para evitar viés na decisão em prol de áreas mais abonadas do país. Gwilliam apresenta ainda outros resultados de pesquisa comportamental:

- viagens longas ( $>50 \mathrm{~km}$ ), de carro - valor do tempo é mais do que duas vezes o valor em viagens curtas (pesquisa na Suécia; resultados semelhantes no Reino Unido e Holanda);

v viagens longas (>50 km), em outros modais - valor do tempo é $20 \%$ maior que o valor em viagens curtas (Suécia; resultados semelhantes no Reino Unido e Holanda);

v quanto maior a economia de tempo versus o tempo total de viagem, maior o valor unitário do tempo economizado;

v tempo de espera (conexões, tempo para chegar ao transporte e espera pelo transporte) - pesquisa na Europa indicou valor 1,3 a 2,0 vezes o valor unitário atribuído ao tempo já em trânsito. Pesquisas no Chile e na Suécia indicaram valores ainda mais altos, mas o Banco Mundial conclui recomendando que tempo de espera não trabalho seja valorado em 1,5 vez o valor do tempo já em trânsito, proporção esta dentro do intervalo 1,5-2,0 sugerido por Grant-Muller e colaboradores (2001);

v tempo de frete - Gwilliam (1997) detalha duas formas de avaliação:

v método do custo - engloba salários, custos trabalhistas, custos fixos, juros sobre o capital empregado nos veículos e no estoque de produtos sendo transportado, custo de licenças de operação/tempo da concessão;

v método de preferência declarada (WTP) dos transportadores/empresas — em situações em que o projeto permite uma reconfiguração completa da logística de transporte. Pesquisa na Suécia mostrou que esse método gerou valores $74 \%$ mais altos que os obtidos no método do custo.

O Banco Mundial recomenda corrigir o valor do tempo pela variação do PIB, a menos que existam estudos mais detalhados com relação à utilidade marginal do tempo. 


\section{Impactos no desenvolvimento econômico}

Segundo Grant-Muller e outros (2001), esta é a área menos desenvolvida em termos de práticas de avaliação econômica. As dificuldades vão desde escolher como operacionalizar os conceitos e objetivos, até o risco de dupla contagem de efeitos, afinal, a redução de custos de transporte para a sociedade, o tráfego induzido pela nova facilidade e os benefícios de tempo e segurança também contribuem, de alguma forma, para o desenvolvimento econômico e social.

Diante da dificuldade desse tema, Grant-Muller e colaboradores (2001) focaram em apenas um item o aumento de emprego, e constataram que menos da metade dos países europeus procuram projetar de forma quantitativa tais impactos. Somente Alemanha, Grécia e Espanha incorporam esse item em avaliações econômicas, sendo que a Alemanha compara o "custo/emprego criado pelo projeto" com custos alternativos de criação de empregos.

Rodovias em regiões agrícolas geram benefícios aos produtores que podem ser estimados usando curvas de utilidade e estimativas de elasticidadepreço. No entanto, em projetos totalmente inovadores, capazes de alterar a logística de transporte e produção, a análise é mais complexa. Trabalhos de Carnemark (1976, apud World Bank, 2005j) e Beenhakker (1983, apud World Bank, 2005j), por exemplo, detalham métodos para projetar tais ganhos, mas o Banco Mundial (World Bank, 2005j, 2005h) alerta que esses métodos requerem muitos dados, conhecimento profundo de agricultura, matrizes complexas de insumos x produção, e têm frequentemente resultado em valores superestimados. Assim, esses métodos têm caído em desuso, dando lugar a análises CEA/MCA/qualitativas, para as quais o Banco Mundial (World Bank, 2005h) sugere pesquisas de mercado, entrevistas, pesquisas de campo e grupos focais para estimar com mais profundidade a capilaridade do projeto na área de estudo.

Em projetos que também têm impacto em zonas residenciais e no mercado imobiliário, o modelo LUTI (Mackie et al., 2001, apud World Bank, 2005h) ajuda a estimar os impactos no uso da terra e na avaliação dos imóveis. Há também modelos computacionais (o próprio LUTI e o CGE) que permitem avaliar o impacto no mercado de trabalho, mas eles são difíceis de aplicar e, portanto, ainda não fazem parte da prática corrente de avaliação (World Bank, 2005e:6).

Uma pesquisa de interesse nessa área foi conduzida pelo Transecon Project, parte do esforço da Comunidade Europeia de uniformização de práticas. Essa pesquisa envolveu estudos de casos múltiplos que procuraram avaliar o impacto post facto de projetos de transporte urbanos — linhas de metrô e de 
trem - em 12 cidades/países da Europa. Os impactos foram analisados à luz de seis grandes temas, um deles o de regeneração urbana, cujos resultados estão detalhados no trabalho de Gospodini (2005). As medidas utilizadas para medir a regeneração urbana, e que podem servir de inspiração para novos trabalhos, foram: percentuais da área total ocupada por residências, comércio, serviços, indústria leve, saúde, lazer etc., a partir de dados obtidos nas prefeituras; investimentos em construção e regeneração de prédios, após o projeto; investimentos em espaços públicos; preços de imóveis e de aluguéis.

O Banco Mundial (World Bank, 2005k) resume a experiência da instituição em analisar o impacto de projetos sobre a população pobre. Esse trabalho começa alertando que alguns projetos são supervalorizados nesse item ou, ainda, acabam gerando efeitos contrários ao esperado nessa população. A superavaliação pode ocorrer, por exemplo, quando o mercado operador ou logístico não é competitivo, de modo que as economias auferidas não são repassadas integralmente para a população. Um exemplo de efeito oposto ao desejado seria um novo transporte que valorizasse terrenos residenciais a ponto de provocar a migração de classes mais ricas para o local, empurrando a população pobre para mais longe.

Apesar das limitações anteriormente citadas, uma avaliação econômica que distribua seus resultados e custos entre ganhadores/perdedores, estratificados por renda, ajuda a estimar se as grandes metas de redução de pobreza serão atingidas, por meio de alguns índices.

Índice de redução da pobreza (IRP) (ADB, 2001, apud World Bank, 2005k):

\section{$\frac{\text { Beneficios aos pobres }}{\text { Beneficios econômicos totais }}>$ percentual da população abaixo da linha de pobreza}

Coeficientes de distribuição de riqueza propostos pelo Banco Interamericano de Desenvolvimento (apud World Bank, 2005k):

$$
C I D=\frac{\text { número de pobres beneficiados }}{\text { população total beneficiada }}
$$

ou

$$
C I D=\frac{V P L \text { dos resultados para pobres }}{V P L \text { total do projeto }}
$$


ou

$$
C I D=\frac{V P L \text { dos resultados para pobres }}{\text { VPL total do projeto }- \text { VPL do governo }}
$$

Análise progressiva/regressiva (Crawford, 2000, apud World Bank, 2005k): estratifica-se a população por renda, distribuem-se os ganhos líquidos de cada estrato.

Índice B/G: Ravallion (1999, apud World Bank, 2005k) propôs um índice mais complexo, composto pela soma dos ganhos relativos da população pobre em relação à geração de trabalho, aumento salarial, benefícios indiretos, versus o gasto público no projeto.

\section{Taxa de desconto econômico}

O Banco Mundial recomenda em seus projetos um custo de oportunidade de capital de $12 \%$ a.a., remuneração esperada para os recursos do banco. A justificativa para o uso de uma taxa de desconto tão alta para a valoração econômica é que dada a escassez de recursos para investimento, faz-se necessário priorizar os projetos que oferecem maior rentabilidade. Os manuais do Banco Mundial apresentam inclusive vários exemplos em que tanto a avaliação econômica quanto a avaliação financeira usam a mesma taxa de desconto, o que não parece fazer muito sentido, dado que os objetivos de cada avaliação são diferentes, assim como a volatilidade dos resultados.

No entanto, o próprio Banco Mundial (World Bank, 2005a) alerta que, em vez da taxa recomendada de $12 \%$ a.a., a avaliação econômica poderia usar taxas que reflitam o custo marginal de investimento no país, isto é, a remuneração pela qual os poupadores se dispõem a restringir o consumo (preferência social no tempo - PST), ou o custo de oportunidade do capital (COC). O WBH (1996) detalha mais esse aspecto, alertando que a taxa de desconto do projeto poderia ter seu valor econômico calculado utilizando-se um custosombra dependente do nível de investimento e poupança no país, dos custos de capital corporativo e de aplicação (pré e pós-tributos) e das respectivas elasticidades.

$\mathrm{Na}$ avaliação financeira, por outro lado, a taxa de desconto deve refletir a percepção de risco do projeto, vis-à-vis as taxas praticadas pelo mercado em geral. Assim, o valor presente líquido do projeto obtido na avaliação 
financeira será diferente do VPL obtido na avaliação econômica, não só porque há nesta última a inclusão e exclusão de diversos itens, mas também porque a taxa de desconto do fluxo é diferente - e maior - na avaliação financeira (World Bank, 2005d:2). Uma taxa bem mais baixa que a de mercado faz sentido em avaliações econômicas, dado que um governo, ou uma sociedade, tem uma capacidade de diversificação de riscos muito maior do que um investidor privado. Assim, o valor em risco para a sociedade e para um governo é proporcionalmente muito menor que a de um investidor privado, mesmo que as volatilidades dos fluxos econômico e financeiro do projeto sejam iguais.

A literatura sobre taxas de descontos em projetos públicos é extensa e em geral critica regras práticas para a taxa de desconto (rules of thumb). Mendelsohn (1981), em sua discussão sobre as proposições de Bradford (1975) para a escolha da taxa de desconto, conclui que o modelo de Bradford chega a valores muito baixos, ou, ainda, que se a PST for usada, a tendência é subavaliar significativamente o custo de oportunidade de um investimento público. $\mathrm{O}$ autor conclui que o cálculo da taxa de desconto ótima é muito difícil, mas precisaria ser feito, e que usar uma taxa de desconto única não pode ser satisfatório para quaisquer circunstâncias. Sharma (1983) e Mendelsohn (1983) apresentam uma discussão sobre a proposição original de Mendelsohn (1981), demonstrando que há campo para divergências nessa área. Liu (2003) lembra que as discussões envolvendo a taxa de desconto de projetos sociais são polarizadas em dois grandes temas: o custo marginal - que foca $o$ custo de receitas adicionais do governo, em um ambiente estático - e a taxa de desconto social (ou preço-sombra), que foca em como descontar os fluxos futuros de custos e benefícios, enfatizando, portanto, o custo dos recursos. O autor propõe uma forma de unir os dois temas dinamicamente, usando o custo marginal de recursos públicos em multiperíodos.

Como essa complexidade tem se refletido nas taxas de desconto utilizadas na prática? Odgaard e outros (2005) apresentam as taxas usadas para descontar fluxos em avaliações econômicas na Europa, que variam de $2 \%$ a $3 \%$ a.a. na Áustria e Suíça a $12 \%$ a.a. em Chipre. Na média, a taxa de desconto fica em $5 \%$ a.a., bem abaixo, portanto, dos $12 \%$ a.a. utilizados pelo Banco Mundial. Apenas nove dos 25 países europeus listados nesse trabalho incluem na taxa de desconto um prêmio pelo risco do projeto. Assim, não há ainda unanimidade, nem mesmo entre os países desenvolvidos, sobre que taxas utilizar, embora exista orientação na Comunidade Europeia para usar taxas entre $3 \%$ e $5 \%$ a.a. Aparentemente, a complexidade e precisão deu lugar a regras práticas 


\section{Brasil: práticas atuais de avaliação econômica de projetos de transporte}

Foi analisado um documento, de caráter orientador e não de norma, publicado pelo IPR, ligado ao DNIT (2006b). Ele é bastante completo com relação aos aspectos de engenharia e tráfego, mas dedica-se pouco aos procedimentos que devem ser adotados em avaliações econômicas de projetos.

De qualquer forma, foram encontradas algumas diretrizes que se aproximam das identificadas na literatura para avaliações econômicas, tais como identificação de tráfego desviado/gerado, dedução de impostos incidentes para determinar os custos econômicos, utilização de preços-sombra; quantificação do custo de tempo de viagem, diferenciando-o entre viagens a passeio e a trabalho; benefício do tempo de frete; custo de operação de veículos calculados pelo HDM-4 do Banco Mundial. Alerta-se também para o risco de dupla contagem de benefícios.

Por outro lado, foram identificados os seguintes pontos em que a prática local diverge das práticas em outros países, de acordo com a literatura revisada: custos e benefícios não são apropriados entre as partes afetadas (ganhadores/perdedores) e no custo de tempo de viagem utiliza-se o salário médio dos usuários da rodovia, não o do país. No entanto, o manual deixa claro que a avaliação econômica serve ao objetivo de comparar alternativas para o mesmo trecho. Pressupõe-se, portanto, que o projeto já passou por uma triagem inicial, utilizando outros métodos, talvez CEA ou MCA. Além dos pontos acima, o DNIT/IPR (2006b) não detalha como calcular os diversos componentes do tempo, porém é razoável supor que os softwares utilizados já apresentem os parâmetros base mencionados na literatura.

Finalmente, a inclusão de benefícios indiretos é estimulada apenas em avaliações de projetos em trajetos pioneiros, não em áreas já desenvolvidas. São considerados benefícios indiretos aqueles advindos de:

- crescimento líquido da produção local: não se detalha como proceder, apenas sugerem-se comparações com o rendimento de regiões semelhantes que disponham de infraestrutura adequada de transporte. Há sinalização de que não mais do que $30 \%$ de incremento da produção agropecuária poderia ser considerado;

v valorização de propriedades, sugerindo-se usar como referência os valores em áreas semelhantes, mas que possuam boa infraestrutura de transporte;

- evolução social e distribuição de renda: não se estabelece como proceder. 
Com relação à taxa de desconto, o manual brasileiro recomenda a taxa de $12 \%$ a.a., similar à do Banco Mundial. Não há maiores explicações sobre o racional utilizado para se chegar a esse número relativamente alto. É interessante também notar que o risco do projeto é medido por meio de análises de sensibilidade, porém ignorando benefícios indiretos.

O manual anteriormente citado traz pouca luz ao processo de avaliação econômica e nenhuma orientação palpável quanto ao item segurança/redução de acidentes. No que se refere a este último item, no entanto, o DNIT/IPR contratou serviço de consultoria técnica na área de custos de acidentes (DNIT/ IPR, 2004), que apresentou um estudo bastante detalhado dos custos diretos e indiretos de acidentes no Brasil.

Para estimar o valor de uma vida, VoSL, o DNIT/IPR (2004) utilizou o critério de rendimentos brutos perdidos, obtidos por meio do salário médio estratificado por sexo, região do país e grau de instrução do acidentado. Supôsse que essa renda cresceria a 1,5\% a.a. No caso de acidentes graves, supôs-se a perda de rendimentos durante um ano; em acidentes leves, supôs-se perda de rendimentos durante 15 dias. Os custos de "dor, sofrimento e pesar" foram calculados como percentuais dos custos totais do acidente, seguindo sugestão de Jacobs (1995), já mencionada neste trabalho: acidente fatal, 38\%; acidente grave, 100\%; acidente leve, $8 \%$. Não foi feita, portanto, nenhuma pesquisa WTP, nem para a determinação do VoSL, nem para a alocação de pesos refletindo a gravidade dos acidentes sem fatalidade, porém com feridos. Os valores encontrados nessa pesquisa estão no apêndice 2 .

Vale lembrar aqui o trabalho de Barone e Rebelo (2003) de avaliação dos impactos sociais da linha 4 do Metrô de São Paulo. Impactos como a inclusão no mercado de trabalho de populações periféricas, impactos ambientais, economia de tempo foram considerados no trabalho de forma quantitativa, mas não sob uma perspectiva monetária, CBA, refletindo o que parece ser a prática hoje no país: análises CEA ou MCA.

\section{Limitações observadas e recomendações para a metodologia brasileira}

Os manuais brasileiros para análise de projetos de transporte rodoviário são pouco detalhados e específicos no que se refere às rotinas necessárias a uma avaliação econômica. Não ficam claras as diferenças entre as avaliações financeira e econômica de projetos, tampouco se distribuem os custos e benefícios do projeto entre empresas, governo, consumidores, produtores. Isso dificulta a identificação de ganhadores/perdedores e, portanto, dificulta a identificação de quanto o governo e a iniciativa privada poderiam deter de participação. 
O procedimento de preços-sombra é mencionado, porém não se detalham os procedimentos nem o racional envolvidos, dificultando a aplicação desse importante conceito no processo de avaliação.

Tudo indica que no Brasil não são utilizados métodos WTP, apenas os métodos mais simplificados. Mesmo nestes, fica a dúvida sobre como se calculam alguns valores (por exemplo, viagens a passeio e a trabalho). $\mathrm{O}$ resultado são custos subjetivos bastante inferiores aos encontrados em outros países e esse item deveria merecer maior reflexão. Não há evidência de que a avaliação econômica está sendo usada como instrumento para a escolha de projetos prioritários, nem quais modelos de análise estão sendo aplicados, se CBA, CEA ou MCA.

A taxa de desconto sugerida de $12 \%$ a.a. também mereceria maior discussão. Em um país como o Brasil, com grande volatilidade das taxas de juros, escolher a taxa de desconto para projetos de tão longo prazo é, de fato, um desafio. No entanto, o retorno necessário a projetos de infraestrutura não deveria ser uma taxa que hoje se equipara à taxa de mercado, aí incluídos os impostos. Um valor que consideramos mais razoável para a taxa de desconto — embora ainda carregado de excessiva simplificação — seria a remuneração da poupança, hoje equivalente a 7,5\% a.a.

$\mathrm{O}$ apêndice 3 apresenta um resumo dos parâmetros e práticas que poderiam ser adotados no país, baseado nas práticas utilizadas em outros países. Apesar do custo de pesquisa, estudos WTP para "dor, sofrimento e pesar", por exemplo, agregariam informação importante à análise, especialmente à luz dos trabalhos que mostram que não faria sentido adaptar resultados WTP obtidos em outros países para o Brasil. Recomenda-se, ainda, uma elaboração mais sofisticada do crescimento do poder de compra da população, informação necessária para determinar os rendimentos perdidos devido a acidentes com vítimas, e que foi arbitrado em 1,5\% a.a. no estudo DNIT/IPR (2004).

Nas questões relativas à economia de tempo, recomenda-se definir nos manuais parâmetros claros para cada item, mesmo que replicando aqueles recomendados pelo Banco Mundial. Também nesse quesito, recomenda-se valorar o "tempo de espera", não mencionado nos manuais revistos. Finalmente, recomenda-se que em projetos rurais a valoração do impacto de desenvolvimento econômico seja também baseada em entrevistas e fóruns com empresários e população locais: não chegam a ter os altos custos de estudos WTP, porém são procedimentos que favorecem boas decisões.

Cabe, também, fazer uma sugestão a respeito de melhores práticas em projetos que envolvam participação governamental. Acredita-se que dados de- 
veriam ser coletados pós-projeto, de modo a trazer lições para a sociedade e para os tomadores de decisão. Uma "avaliação de impactos", conforme proposto pelo Banco Mundial (World Bank, 2007c), deveria ser feita de modo a avaliar se o projeto se provou relevante, eficaz, eficiente, sustentável e, ainda, se favoreceu o melhor uso de recursos do país com uma boa performance financeira para o governo e para eventuais parceiros privados do projeto. Essa análise permite compor uma base de dados que serão necessários à avaliação de novos projetos como, por exemplo, índices de elasticidade, estatísticas de segurança e de desenvolvimento econômico, por exemplo. Vale lembrar, ainda, que uma análise com esse objetivo deve incluir não só a área/grupo beneficiado, mas também uma área/grupo de controle, de modo a avaliar se os impactos observados foram causados por motivos outros que não o projeto propriamente dito. Sem isso, os resultados seriam de pouquíssima utilidade.

\section{Conclusões}

Nesta pesquisa analisamos o estado da arte em avaliação econômica de projetos de transporte, e constatamos que existem ainda significativas dificuldades em uniformizar práticas e instituir critérios exclusivamente monetários como instrumento de decisão. Na maior parte dos países analisados, há uma tendência bastante forte de se utilizar critérios monetários (CBA), sempre que possível, porém também se verificou grande incidência de análises incorporando outros critérios, ainda quantitativos mas não monetários, tais como o CEA e o MCA. Nos países europeus há, no entanto, unanimidade quanto ao uso de avaliações econômicas, complementares à avaliação puramente financeira de projetos e quanto ao uso de CBA para avaliar os itens de segurança e de economia de tempo.

No Brasil essa metodologia ainda está nos seus primórdios, e os manuais e trabalhos analisados não oferecem nível de detalhe que permita a sua aplicação prática, embora mencionem as diretrizes que devem ser seguidas. Tentativas recentes de detalhamento dos procedimentos e de monetização de impactos sociais mostram que o país está buscando atingir melhores práticas, mas em geral ainda se adotam procedimentos bastante simplificados no cálculo de externalidades. Além das recomendações mencionadas na seção anterior, recomenda-se também o acompanhamento sistemático dos impactos sociais de projetos, de modo a criar um banco de dados com lições aprendidas que possam indicar melhores caminhos em projetos futuros.

Vale notar, contudo, que são sugestões de novos caminhos que, apenas quando testados em casos práticos, poderão se mostrar factíveis. Cabe aqui lembrar uma importante observação de Grant-Muller e outros (2001:252), 
grandes defensores de métodos monetários como o CBA, mas também com longa experiência prática na sua aplicação:

O que importa é que alguma forma metodológica coerente, consistente e auditável avalie esses impactos, e que eles sejam apresentados de uma maneira que facilite o processo de análise, ao invés de obscurecê-lo. Uma boa e bem arrazoada descrição dos impactos seguindo o arcabouço MCA (análise multicritérios) pode ser infinitamente melhor que uma análise CBA baseada em dados numéricos muito fracos.

\section{Referências}

ARROW, K. J. Uncertainty and welfare economics of medical care. American Economic Review, v. 53, n. 5, p. 941-973, 1963.

BEESLEY, M. E. The value of time spent in travelling: some new evidence. Economica, New Series, v. 32, n. 126, p. 174-185, May 1965.

BARONE, M.; REBELO, J. Potential impact of Metro's line 4 on poverty in the São Paulo Metropolitan Region (SPMR). World Bank. 2003. Disponível em: <www.worldbank. org/transport/urbtrans/poverty_14_sp.pdf >. Acesso em: 25 maio 2007.

BRADFORD, D. Constraints on government investment opportunities and the choice of discount rates. American Economic Review, n. 65, p. 887-899, Dec. 1975.

DNIT/IPR (Departamento Nacional de Infraestrutura de Transportes/Instituto de Pesquisas Rodoviárias). Serviços de consultoria para assessoria técnica na área de custos de acidentes. Relatório final. Revisão de metodologias e resultados. 2004. Disponível em: <www1.dnit.gov.br/arquivos_internet/ipr/ipr_new/manuais/> Acesso em: 12 jun. 2007.

. Apresentação de C. J. Chequer, coordenador do IPR. In: SEMINÁRIO SOBRE SEGURANÇA EM RODOVIAS, 1. Anais... 2006a. Disponível em: <www1.dnit.gov. br/ipr_new/aconteceu.htm>. Acesso em: 30 abr. 2007.

. Diretrizes básicas para elaboração de estudos e projetos rodoviários: escopos básicos e instruções de serviço. Publicação IPR 726. 2006b. Disponível em: <www1. dnit. gov.br/arquivos_internet/ipr/ipr_new/manuais/diretrizes_basicas_instrucoes_servicos.pdf $>$. Acesso em: 30 abr. 2006.

DODGSON, J. S. et al. Multi-criteria analysis: a manual. London: Department of the Environment, Transport and the Regions, 2001. Ch. 3. Disponível em: <www. communities.gov.uk/index.asp?id=1142251>. Acesso em: 12 jun. 2005. 
GRANT-MULLER, S. M. et al. Economic appraisal of European transport projects: the state-of-the-art revisited. Transport Reviews, v. 21, n. 2, p. 237-261, 2001.

GOSPODINI, A. Urban development, redevelopment and regeneration encouraged by transport infrastructure projects: the case study of 12 European cities. European Planning Studies, v. 13, n. 7, Oct. 2005.

GWILLIAN, K. M. The value of time in economic evaluation of transport projects: lessons from recent research. Infrastructure notes. Transport NO.OT-5. 1997. World Bank. Disponível em: <http://siteresources.worldbank.org/INTTRANSPORT/ Resources/336291-1119275973157/td-ot5.pdf>. Acesso em: 12 jun. 2007.

JONES-LEE, M. W.; HAMMERTON, M.; PHILIPS, P. R. The value of safety: results of a national survey. The Economic Journal, v. 95, n. 377, p. 49-72, Mar. 1985.

KAHNEMAN, D.; SLOVIC, P.; TVERSKY, A. Judgement under uncertainty: heuristics and biases. 22. ed. Cambridge: Cambridge University Press, 1982.

KOYAMA, S.; TAKEUCHI, K. Economic valuation of road injuries in Japan by standard gamble. Environmental Economics and Policy Studies, n. 6, p. 119-146, 2004.

LIU, L. A marginal cost of funds approach to multi-period public project evaluation: implications for the social discount rate. Journal of Public Economics, v. 87, n. 7-8, p. 1707-1718, Aug. 2003.

MARKANDYA, A. The valuation of health impacts in developing countries. Planejamento e Políticas Públicas, Ipea, n. 18, dez. 1998. Disponível em: <www.ipea.gov. br/pub/ppp/ppp18/Parte4.doc>. Acesso em: 12 jun. 2007.

MENDELSOHN, R. The choice of discount rates for public projects. The American Economic Review, v. 71, n. 1, p. 239-241, Mar. 1981.

. The choice of discount rates for public projects. The American Economic Review, v. 73, n. 3, p. 499-500, June 1983.

ODGAARD, T. et al. Current practice in project appraisal in Europe. 2005. Disponível em: <http://heatco.ier.uni-suttgart.de/deliverables/deliverable1>. Acesso em: 5 jun. 2007.

PAIXÃO, L. A. R. O impacto da violência nos preços dos imóveis comerciais de Belo Horizonte: uma abordagem hedônica. Economia Aplicada, v. 13, n. 1, p. 125-152, jan./mar. 2009.

SAMUELSON, P. The pure theory or public expenditure. The Review of Economics \& Statistics, v. 36, n. 4, p. 387-389, Nov. 1954.

SHARMA, J. L. The choice of discount rates for public projects: comment. The American Economic Review, v. 73, n. 3, p. 497-498, June 1983. 
UNITED NATIONS. Department of Economic and Social Affairs. Report on the aggregation of indicators of sustainable development. Background paper for the ninth session of the Commission on Sustainable Development. Disponível em: <www.un.org/esa/sustdev/ csd/csd9-aisd-bp.pdf>. Acesso em: 15 jun. 2007.

VILLAS, M. V.; MACEDO-SOARES, T. D. L. A.; RUSSO, G. M. Bibliografical research method for business administration studies: a model based on scientific journal ranking. Brazilian Administration Review, v. 5, n. 2, p. 139-159, Apr./June 2008. Disponível em: <www.anpad.org.br/bar>. Acesso em: jul. 2008.

WORLD BANK. Economic analyses in transport project and program appraisal. Disponível em: <www.worldbank.org/transport/pol_econ/econ_apr.htm>. Acesso em: 30 abr. 1997a.

. Handbook on economic analysis of investment operations. WBH. May 1996. Disponível em: <http://rru.worldbank.org/Documents/Toolkits/Highways/pdf/82. pdf $>$. Acesso em: 30 abr. 2007b.

. Independent Evaluation Group (IEG). Impact evaluation. Disponível em: <www.worldbank.org/ieg/ie/>. Acesso em: 30 abr. 2007c.

. Transport Economics \& Sector Policy. Economic analyses in transport project and program appraisal. Disponível em: <www.worldbank.org/transport/pol_econ/ econ_apr.htm>. Acesso em: 30 abr. 2007d.

. Transport Economics \& Sector Policy. Economic appraisal: accident costs in transport. Disponível em: <www.worldbank.org/transport/pol_econ/econ_apr. htm >. Acesso em: 30 abr. 2007e.

.TRN-5. Transport Notes. A framework for the economic evaluation of transport projects. 2005a. Disponível em: <web.worldbank.org/WBSITE/EXTERNAL/TOPICS/ EXTTRANSPORT/EXTTES/0,,contentMDK:20464962 isCURL:Y menuPK:116 5113 pagePK:148956 piPK:216618 theSitePK:338532,00.html>. Acesso em: 30 abr. $2007 f$.

. TRN-8. Transport Notes. Fiscal impacts: the fiscal impacts of transport investments. 2005b. Disponível em: < web.worldbank.org/WBSITE/EXTERNAL/TOPICS/ EXTTRANSPORT/EXTTES/0,,contentMDK:20464962 isCURL:Y menuPK:116 5113 pagePK:148956 piPK:216618 theSitePK:338532,00.html>. Acesso em: 30 abr. $2007 \mathrm{~g}$.

. TRN-9. Transport Notes. Where to use cost effectiveness techniques rather than cost benefit analysis. 2005c. Disponível em: <web.worldbank.org/WBSITE/EXTERNAL/TOPICS/EXTTRANSPORT/EXTTES/0,,contentMDK:20464962 isCURL: Y menuPK:1165113 pagePK:148956 piPK:216618 theSitePK:338532,00. html>. Acesso em: 30 abr. 2007h. 
. TRN-10. Transport Notes. Relationship between financial and economic evaluations for different types of project. 2005d. Disponível em: <web. worldbank.org/WBSITE/EXTERNAL/TOPICS/EXTTRANSPORT/EXTTES/ 0,,contentMDK:20464962 isCURL:Y menuPK:1165113 pagePK:148956 piP K:216618 theSitePK:338532,00.html>. Acesso em: 30 abr. 2007i.

. TRN-11. Transport Notes. Treatment of induced traffic. 2005e. Disponível em: < web.worldbank.org/WBSITE/EXTERNAL/TOPICS/EXTTRANSPORT/ EXTTES/0,,contentMDK:20464962 isCURL:Y menuPK:1165113 pagePK:148 956 piPK:216618 theSitePK:338532,00.html>. Acesso em: 30 abr. 2007j.

. TRN-15. Transport Notes. Valuation of time savings. 2005f. Disponível em: <web.worldbank.org/WBSITE/EXTERNAL/TOPICS/EXTTRANSPORT/EXTTES/ 0, contentMDK:20464962 isCURL:Y menuPK:1165113 pagePK:148956 piP K:216618 theSitePK:338532,00.html>. Acesso em: 30 abr. 2007k.

. TRN-16. Transport Notes. Valuation of accident reduction. 2005g. Disponível em: < web.worldbank.org/WBSITE/EXTERNAL/TOPICS/EXTTRANSPORT/ EXTTES/0,,contentMDK:20464962 isCURL:Y menuPK:1165113 pagePK:1489 56 piPK:216618 theSitePK:338532,00.html>. Acesso em: 30 abr. 20071.

. TRN-19. Transport Notes. Projects with significant expected restructuring effects. 2005h. Disponível em: < web.worldbank.org/WBSITE/EXTERNAL/TOPICS/ EXTTRANSPORT/EXTTES/0,,contentMDK:20464962 isCURL:Y menuPK:116 5113 pagePK:148956 piPK:216618 theSitePK:338532,00.html>. Acesso em: 30 abr. $2007 \mathrm{~m}$.

. TRN-20. Transport Notes. Evaluation of public sector contributions to public-private partnership projects. 2005i. Disponível em: <web.worldbank. org/WBSITE/EXTERNAL/TOPICS/EXTTRAN SPORT/EXTTES/0,, contentMDK:20464962 isCURL:Y menuPK:1165113 pagePK:148956 piPK: 216618 theSitePK:338532,00.html>. Acesso em: 30 abr. 2007n.

. TRN-21. Transport Notes. Low volume roads. 2005j. Disponível em: <web.worldbank.org/WBSITE/EXTERNAL/TOPICS/EXTTRANSPORT/EXTTES/ 0,,contentMDK:20464962 isCURL:Y menuPK:1165113 pagePK:148956 piP K:216618 theSitePK:338532,00.html>. Acesso em: 30 abr. 2007o.

. TRN-26. Transport Notes. Distribution of benefits and impacts on poor people. 2005k. Disponível em: <web.worldbank.org/WBSITE/EXTERNAL/TOPICS/EXTTRANSPORT/EXTTES/0, contentMDK:20464962 isCURL:Y menuPK: 1165113 pagePK:148956 piPK:216618 theSitePK:338532,00.html>. Acesso em: 30 abr. 2007p. 


\section{Apêndice 1}

\section{Pesquisas e práticas adotadas com relação à segurança na literatura}

\begin{tabular}{|c|c|c|c|c|c|}
\hline País & Fonte da informação & \multicolumn{4}{|c|}{ Resultados } \\
\hline \multirow[t]{2}{*}{ Inglaterra } & $\begin{array}{l}\text { Jones-Lee (1985) } \\
\text { v Estudo WTP } \\
\text { • } 1.057 \text { entrevistas }\end{array}$ & \multicolumn{4}{|c|}{$\begin{array}{l}\text { VoSL }=£ 800 \text { mil, baseado na mediana dos resultados; } \\
\text { no entanto, uma das medidas indicou } £ 500 \text { mil, que apa- } \\
\text { rentemente foi o número adotado pelo governo britânico } \\
\text { (moeda de 1985) }\end{array}$} \\
\hline & $\begin{array}{l}37 \text { perguntas } / 45 \mathrm{~min} \\
210 \text { entrevistas um mês } \\
\text { depois, para verificar consis- } \\
\text { tência temporal }\end{array}$ & \multicolumn{4}{|c|}{ Obs.: antes, o valor utilizado na Inglaterra era de $£ 180$ mil. } \\
\hline Europa & Grant-Muller et al. (2001) & \multicolumn{4}{|c|}{$\begin{array}{l}\text { - Grécia, Portugal, Espanha, Holanda: } € 35 \text { mil a } € 199 \text { mil } \\
\text { vélgica, Dinamarca, França: } € 200 \text { mil a } € 749 \text { mil } \\
\text { - Áustria, Finlândia, Alemanha, Irlanda, Suécia, Reino Unido: } \\
€ 750 \text { mil a } € 600 \text { mil }\end{array}$} \\
\hline \multirow[t]{5}{*}{ Japão } & \multirow{5}{*}{$\begin{array}{l}\text { Koyama e Takeuchi (2004) } \\
\text { - Critério adotado pelo governo } \\
\text { japonês em } 1997 \\
\text { v Usaram teoria dos jogos e } \\
\text { Jones-Lee para definir pesos } \\
\text { para acidentes não fatais } \\
\text { v } 424 \text { questionários válidos + } \\
295 \text { para estudantes } \\
\text { - Quatro tipos de questionário } \\
\text { - Arbitraram VoSL em } ¥ 150 \text { mi- } \\
\text { Ihões ( VoSL da Inglaterra, e } \\
\text { bem abaixo de outros valores } \\
\text { WTP obtidos no Japão para } \\
\text { tratamento de água) }\end{array}$} & \multicolumn{4}{|c|}{$\begin{array}{l}\text { Governo avalia segurança e tempo através de processo que } \\
\text { não usa WTP, apenas perda de receita líquida (renda menos } \\
\text { consumo do indivíduo); neste método, custo humano de } \\
\text { acidentes }=40 \% \text { do custo total de acidentes }\end{array}$} \\
\hline & & \begin{tabular}{|l} 
Valores \\
encontrados \\
$(¥ \mathrm{mil})$
\end{tabular} & $\begin{array}{l}\text { Acidentes } \\
\text { fatais }\end{array}$ & $\begin{array}{l}\text { Acidentes } \\
\text { graves }\end{array}$ & $\begin{array}{l}\text { Acidentes } \\
\text { leves }\end{array}$ \\
\hline & & $\begin{array}{l}\text { Governo } \\
\text { japonês }\end{array}$ & 33.520 & 11.520 & 650 \\
\hline & & $\begin{array}{l}\text { Koyama e } \\
\text { Takeuchi }\end{array}$ & 150.000 & 33.600 & 2.250 \\
\hline & & & & & \\
\hline Brasil & $\begin{array}{l}\text { Markandya (1998) } \\
\text { - Estimou VoSL com base } \\
\text { no VoSL usado nos EUA } \\
\text { em } 1995 \text { (US } \$ 4 \text { milhões), } \\
\text { corrigindo-o pelos PPP PIB } \\
\text { dos dois países e usando } \\
\text { elasticidades } \xi=1,0 \text { e 0,35 } \\
\text { DNIT/IPR (2004) }\end{array}$ & \multicolumn{4}{|c|}{$\begin{array}{l}\xi=1,0: \text { VoSL }=\text { US\$ } 835.000(1995) \\
\xi=0,35: \text { VoSL }=\text { US\$2.311.000 (1995) } \\
\text { US\$ 110.000 (moeda de 2000) }\end{array}$} \\
\hline
\end{tabular}

WTP $=$ disposição para pagar.

VoSL $=$ valor de uma vida estatística.

PPP PIB = produto interno bruto, ajustado pelo poder de compra da população. 


\section{Apêndice 2}

\section{Custos de acidentes rodoviários no Brasil em 2000 - custo por gravidade do acidente (R\$ milhões de 2000)}

\begin{tabular}{|lrccr|}
\hline \multirow{2}{*}{ Componentes do custo } & \multicolumn{3}{c}{ Tipos de acidentes } & \multirow{2}{*}{ Custo total } \\
\cline { 2 - 4 } & Com mortos & Com feridos & Sem vítimas & \\
\hline Perda de rendimentos futuros & 724 & 229 & - & 954 \\
Danos aos veículos & 49 & 152 & 144 & 345 \\
Médico-hospitalares & 52 & 1.186 & & 1.238 \\
Administração de seguros & 12 & 6 & 4 & 22 \\
Atendimento & 10 & 46 & 96 & 152 \\
Danos ao patrimônio & $<1$ & $<1$ & $<1$ & $<1$ \\
Funerais & 7 & - & - & 7 \\
Processos judiciais & 22 & - & - & 22 \\
Congestionamento & 17 & 202 & 35 & 254 \\
Dor, pesar e sofrimento & 339 & 401 & - & 740 \\
Valor total (R\$) & 1.232 & 2.221 & 279 & 3.733 \\
Valor total (US\$) & 632 & 1.139 & 143 & 1.914 \\
Número de acidentes & 4.956 & 31.728 & 71.913 & 108.597 \\
Custo/acidente (R\$ mil) & 249 & 70 & 4 & 34 \\
Custo/acidente (US\$ mil) & 128 & 36 & 2 & 18 \\
\hline
\end{tabular}

Fonte: DNIT/IPR (2004). 


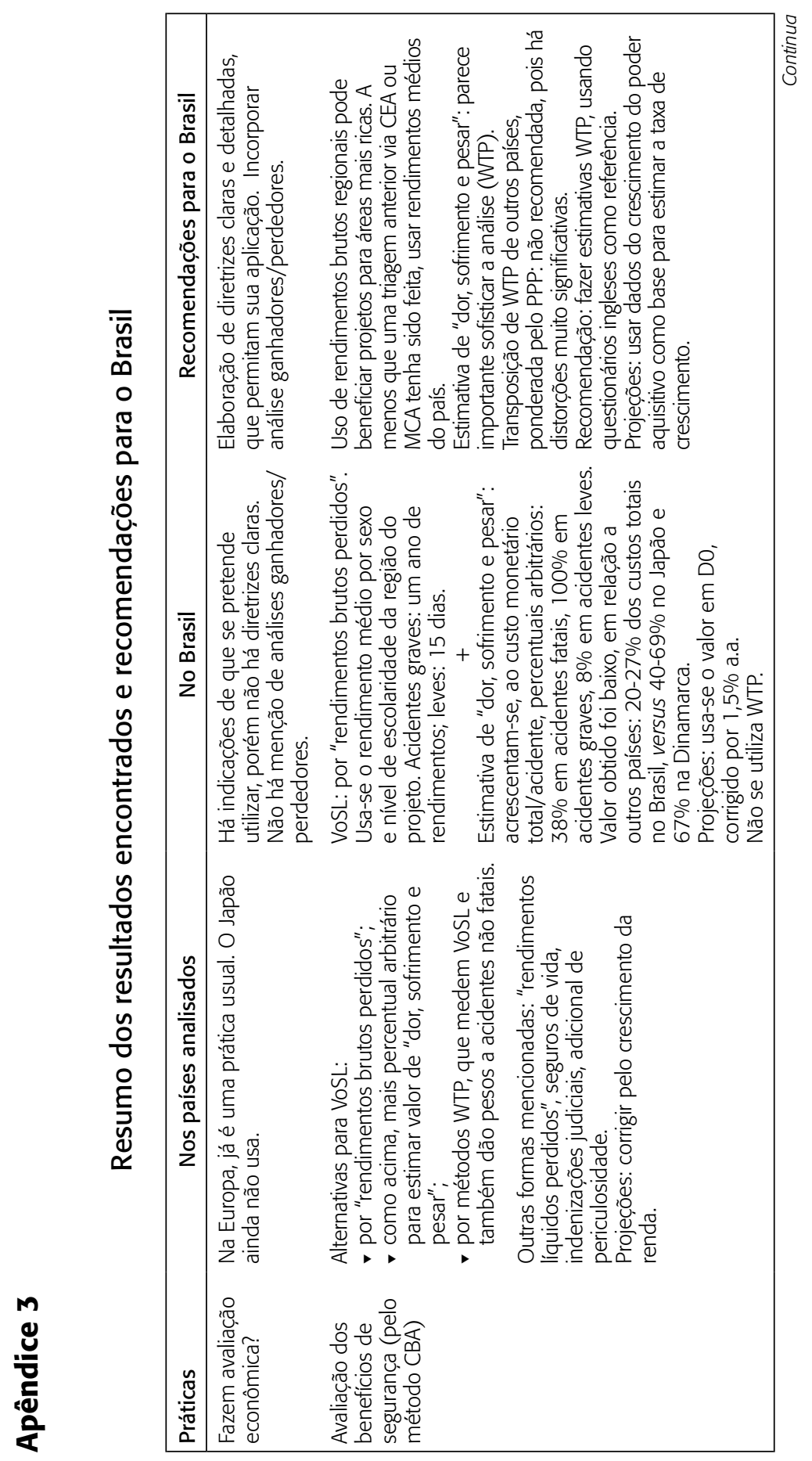




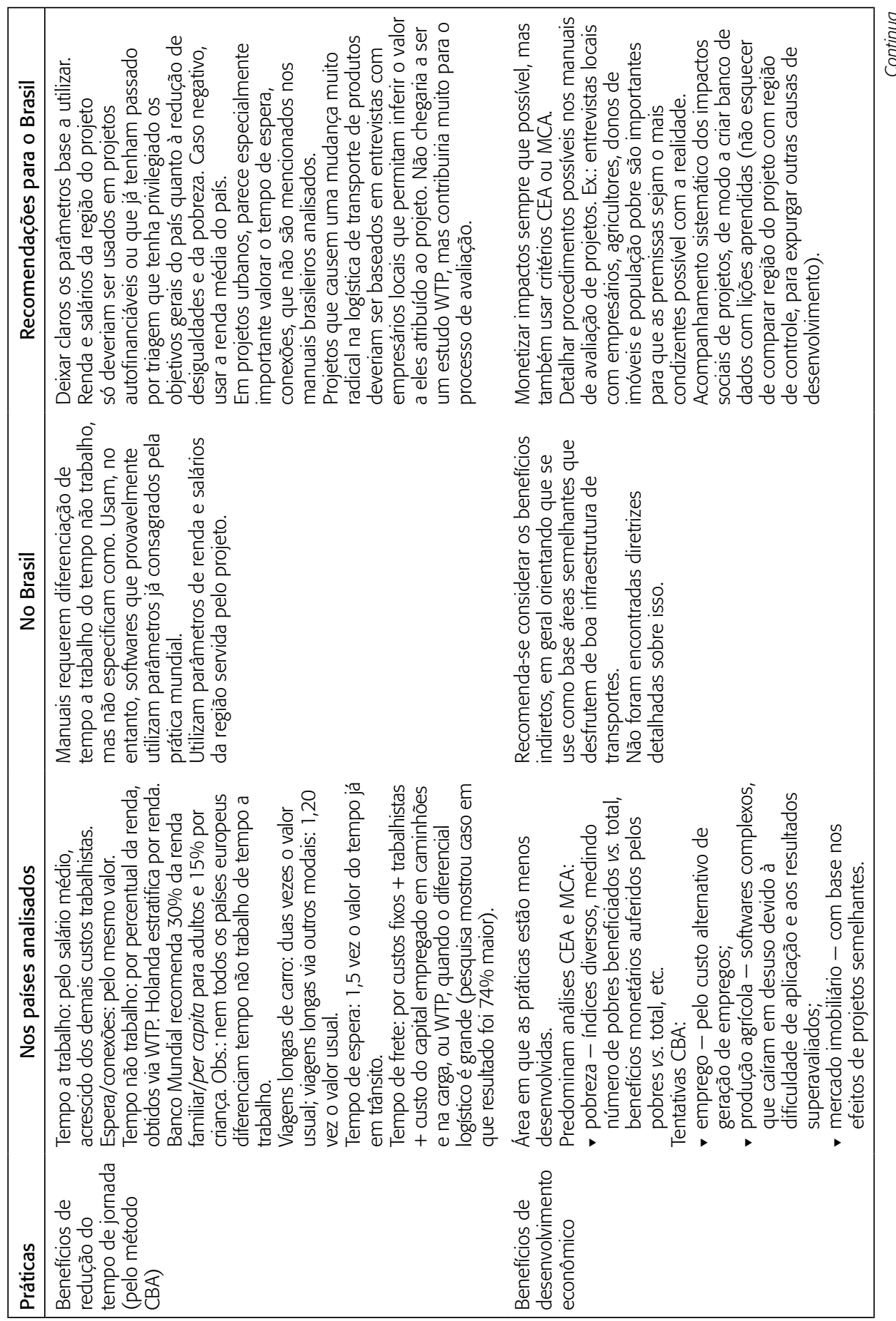




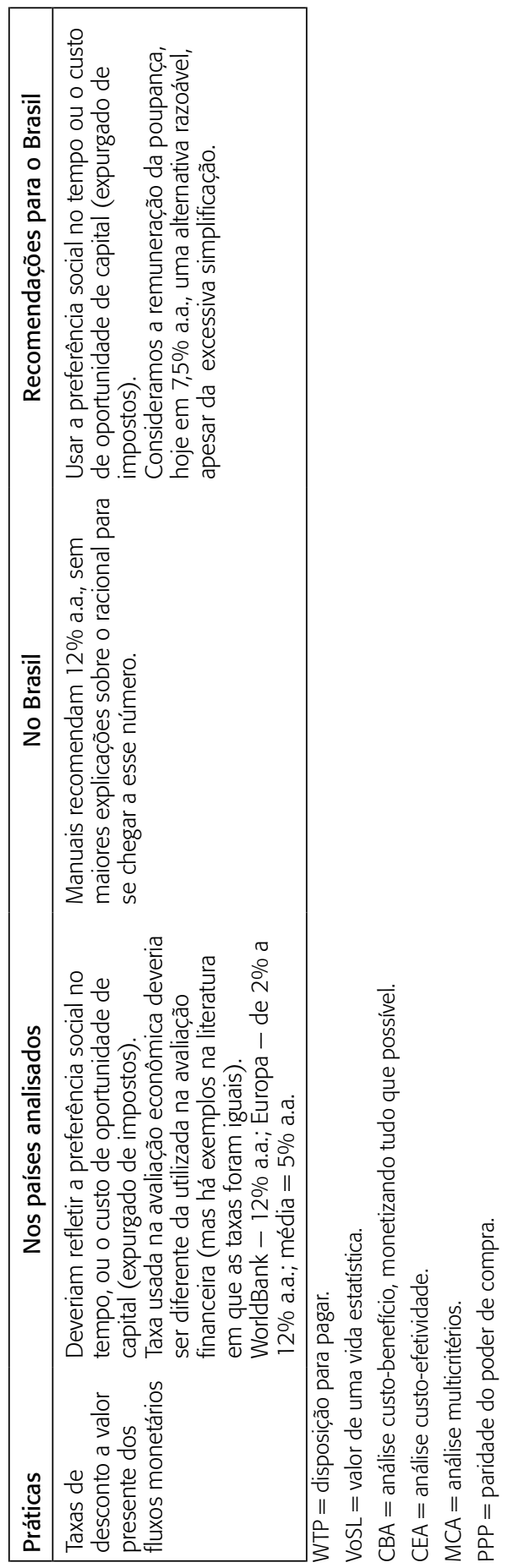

RAP - RIO DE JANEIRO 44(1):87-117, JAN./FEV. 2010 